\title{
Evaluating the Phoenix dactylifera L. Biochemical Changes Associated With Its Maturation
}

\author{
Saad Alqarni ${ }^{1} \&$ Mohammad D. Bazzi ${ }^{2}$ \\ ${ }^{1}$ Department of Basic Sciences, College of Science and Health Professions, King Saud bin Abdulaziz University \\ for Health Sciences (KSAU-HS), Riyadh, Saudi Arabia \\ ${ }^{2}$ Department of Biochemistry, College of Science, King Saud University, Riyadh, Saudi Arabia \\ Correspondence: Saad Alqarni, Department of Basic Sciences, College of Science and Health Professions, King \\ Saud bin Abdulaziz University for Health Sciences (KSAU-HS), Riyadh, Saudi Arabia. E-mail: \\ alqarnisa@ksau-hs.edu.sa
}

Received: September 19, 2018

Accepted: December 21, 2018

Online Published: February 15, 2019

doi:10.5539/jas.v11n3p614

URL: https://doi.org/10.5539/jas.v11n3p614

\begin{abstract}
The present study explains the maturation stage of the Sukkari and Hilwa along with the associated biochemical changes. A total of 10 different samples were studied of the Sukkari and Hilwa dates in total, in which each represents different maturation stage. The outcomes of the study showed that the changes were emerging due to the proteins and enzymes present in dates. The study showed that the date fruit goes through different biochemical changes with its maturation, which can assist in the expansion of the date fruit cultivation.
\end{abstract}

Keywords: biochemical changes, date fruits, hilwa date, maturation, sukkari date

\section{Introduction}

The palm family, also called Arecaceae, constitutes of various genera and species, which range about 183 and above 2400 respectively (Al-Alawi et al., 2017). Phoenix dactylifera L., also known as date fruit, is a nutritious plant which is found from countries located in the regions of North America to the Middle East encompassing the Arabian Gulf countries (Trabzuni et al., 2014). Date palm trees are excessively nutritious and are incredibly rich in minerals, carbohydrates, amino acids and dietary fibres (Eid et al., 2013). The fruit is cultivated in a significant amount in the region of Saudi Arabia and makes earnings of about USD 500 million (Al-Khalifah, 2012). The date fruits based on their different composition in terms of chemical and phenolic as well as capabilities for antioxidant vary from each other (Benmeddour et al., 2013).

The date palm encompasses an array of polyphenol. The fruits softening and maturation capabilities are dependent on the cell-wall degradation as well as the polysaccharides particularly concerning the pectins, by several classes of degradative enzymes (Rastegar et al., 2012). The Polyphenol oxidase (PPO), recognized as the bifunctional copper-protein complex, is found in the date palm to catalyse the catecholase and cresolase reactions. This catalytic characteristic assists in the fruit maturation. Similar is the effect produced in the amylase, pectinase, and cellulase reactions, which are often used for the conversion of polysaccharides into oligo and monosaccharides (Torun et al., 2015).

The date palm cultivators around the world make a total of about 2000, mainly present in the regions of Asia and Middle East. The study of Awad et al. (2011) presents some of the biochemical changes in developing and maturation stages with respect to cultivators. It was found that both late and early cultivators of 'Lonet-Mesaed' and 'Helali' date palm comprise of cellulase, xylanase, polygalacturonase, and $\alpha$-amylase activities. The maturity stage changes are based on various biochemical attributes, which the date fruit comprise of. The cultivars can expand the cultivation of the date fruit that demonstrated the elevated value of the beneficial biochemical attributes (Haider et al., 2014). The polyphenol contents ripping effects have also been evaluated in the study of Eid et al. (2013), which showed that the content was highest in the early maturation stages.

The maturation stages in the date fruit are designated universally accepted Arabic names i.e. Kimri, Khalal, Rutab and Tamar respectively. These stages show the cell division, its elongation i.e. immature green, its fully mature form full-color brown, the soft brown as well as the hard-raisin stage of the maturation of date fruit. The date fruits are basically marketed and harvested at three stages named khalal, rutab, and Tamar, which is based 
on the demand made by the market, their soluble tannin level as well as climatic conditions (Awad, Adel, Al-Qurashi, \& Mohamed, 2011). At the first stage, the color of date fruit is green and it is usually not suitable for eating. In the following second stage, the date fruit turns into yellow or red color and it becomes sweet and consumable.

During the Khalal stage, the date fruit turns into yellow or red color and it becomes sweet and consumable. In the Rutab stage, the date fruit turns into a soft, sweet and delicious form in the majority of the cultivars. The last stage of maturation is Tamar, in which the water of date becomes less than $24 \%$ and it converts to a dark brown color (Baliga et al., 2011). Throughout the maturation stage, the date fruits vary in their physical and chemical characteristics. In the development stage, the weight of date fruit and its flesh increase and reach a maximum point at an immature green stage, which is known as Bisir. However, a slight decrease in the weight and flesh is observed during the maturation process. Based on the biochemical changes associated with the maturation of the date fruit, the present study intends to evaluate the biochemical variations, which take place with the date fruit maturation.

\section{Materials and Methods}

Various types of dates have been selected in this study to evaluate the biochemical changes in the progression of the maturation stages. Starch was purchased from the USA; however, different chemicals were collected from the UK that include 3, 5-Dinitrosalicyclic acid, Carboxymethylcellulose, Coomassie brilliant blue G-250, and sodium chloride catechol. The samples of date fruits were rinsed with distilled water at every stage of maturation. The sample was extracted with buffer, which comprises $50 \mathrm{~mm}$ sodium acetate $(\mathrm{pH}=5.0)$, and $100 \mathrm{ml}$ of $\mathrm{NaCl}$ to determine the sample content of soluble proteins and various enzymatic activities.

\subsection{Soluble Proteins Determination}

Bradford method was used to determine the soluble protein content within the extracts of date fruit extracts (Bradford, 1976). Assays were prepared by mixing the $200 \mu \mathrm{l}$ sample with $800 \mu \mathrm{l}$ Bradford reagent. However, the process of incubation started after five minutes, which measured the absorbance at $595 \mathrm{~nm}$ against blank prepared using $200 \mu \mathrm{l}$ of distilled water. The protein content of samples was calculated from a standard curve using bovine serum albumin (BSA) as a reference. $200 \mu \mathrm{l}$ samples containing 0.0-25 $\mu \mathrm{g}$ BSA were used and the absorbance was plotted against known concentrations of BSA at $595 \mathrm{~nm}$.

\subsection{Polyphenol Oxidase Assay}

Polyphenol oxidase (PPO) activity was assayed using catechol as a substrate. PPO is capable of converting catechol (colourless) to benzoquinone (orange) in the presence of oxygen. Benzoquinone is converted to melanin (dark brown) through slow non-enzymatic reactions. The PPO reaction can be monitored by measuring the changes in absorption at $540 \mathrm{~nm}$. PPO activity in date-fruit extracts was measured in a 4-mL reaction mixture containing $10 \mathrm{~mm}$ sodium phosphate buffer $(\mathrm{pH} 6.5), 10 \mathrm{~mm}$ catechol, and a specified amount of extract. Extracts of the later stages of maturation had high PPO activities, which necessitated the use of small amounts of extract $(50 \mu \mathrm{l})$ in the assays. PPO activity was expressed as $\mathrm{mM}$ products produced per hour per $\mathrm{mL}$ extract. The amount of benzoquinone produced was calculated from the changes in absorption using extinction coefficient $3600 \mathrm{M}-1$ $\mathrm{cm}-1$ for benzoquinone at $540 \mathrm{~nm}$. The high amount of extracts is required for measuring the PPO activities at the earlier stages of maturation $(300 \mu \mathrm{l})$. All assays were conducted at $25{ }^{\circ} \mathrm{C}$ using Ultrospec 2000 spectrophotometer attached to a computer.

\subsection{Amylase, Pectinase, and Cellulase Assays}

The activities of amylase, pectinase, and cellulase have been investigated simultaneously in the parallel assays. The activities of these enzymes have been assessed by measuring the number of sugars, which is generally released during the reaction. The mixture of assay comprised of $200 \mu \mathrm{L}$ desalted extract, $350 \mu \mathrm{L}$ buffer of sodium acetate, and $450 \mu \mathrm{L}$ of the substrate. Dinitrosalicylic acid (DNS) was used to incubate the mixture for 24 hours at room temperature before determining the released reducing sugars (Miller, 1959).

\section{Results}

\subsection{Biochemical Changes in Sukkari Date}

The biochemical changes in Sukkari dates were examined by collecting ten different samples that represented various maturity stages of sukkari date. Various samples showed the definite development of color from green to yellow and then to dark brown. The change in color during the maturation process of Sukkari dates has been illustrated in Figure 1. 

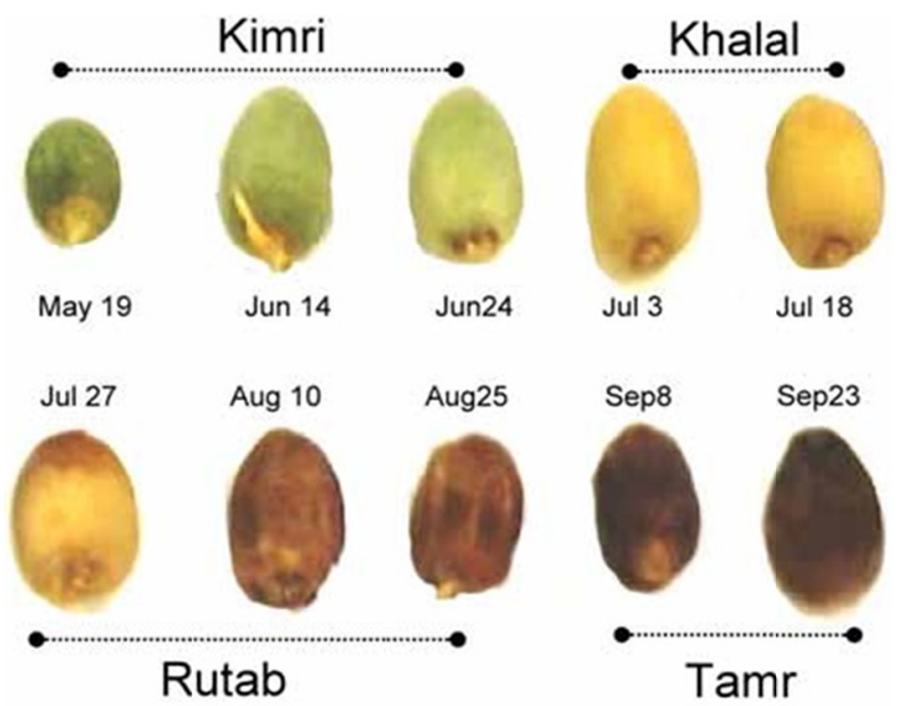

Figure 1. Sukkari date fruit at various stages of maturation

\subsubsection{Weight}

As the Sukkari dates matured, their weight enhanced from $3.7 \mathrm{gm}$ to $9.7 \mathrm{gm}$. However, there is a decrease of 7.4 $\mathrm{gm}$ in the weight of Sukkari dates at the stage of final maturation. Moreover, at the end of the khalal stage and beginning of the rutab stage, the weight of sukkari dates reached maximum, i.e. 9.7 gm (Figure 2).

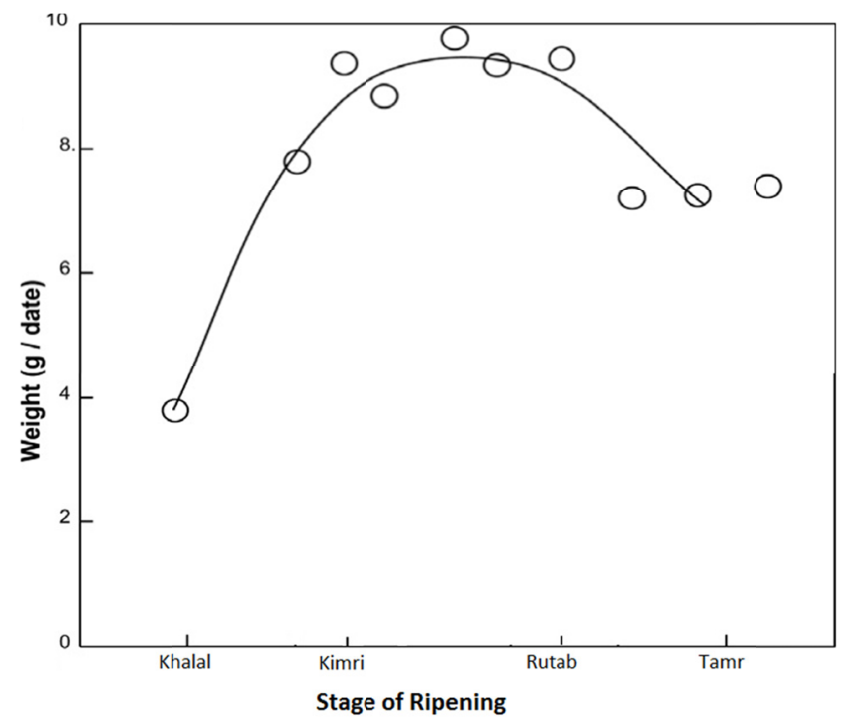

Figure 2. Weight of one sukkari fruit at various stages of maturation

\subsubsection{Protein Content}

It was observed that the protein contents dramatically enhanced at the Tamar stage. The highest content of protein was recorded as $3.4 \mathrm{mg}$ protein $/ \mathrm{g}$, during the last stage of maturity in the samples. Therefore, it was assessed that protein content was lower in sukkari date fruits. The soluble protein content of sukkari dates has been demonstrated in Figure 3. 


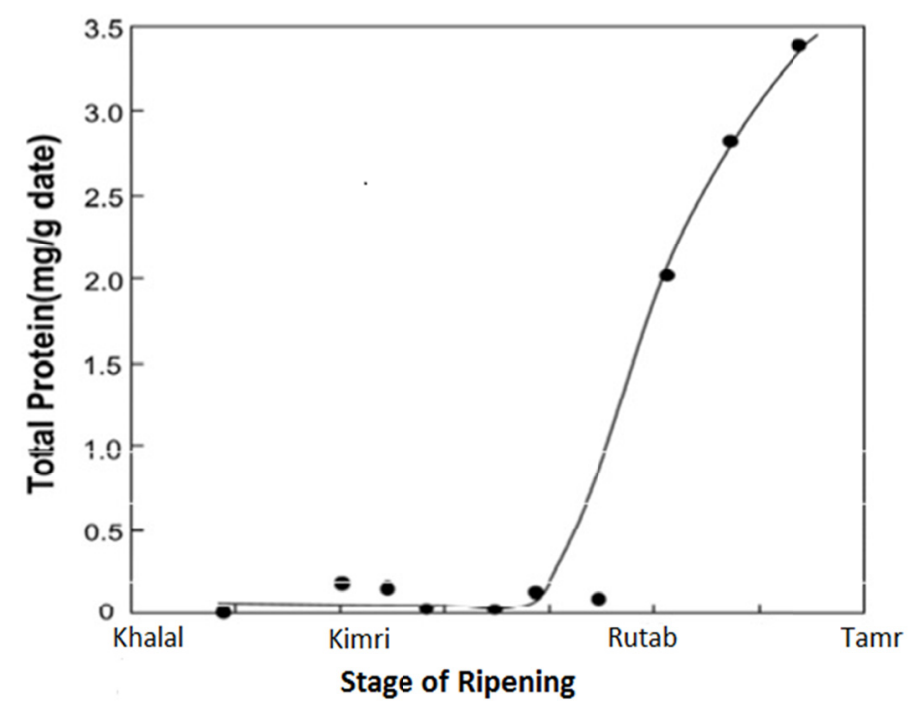

Figure 3. Soluble protein content of sukkari fruit at the various stages of maturation

\subsubsection{Activity of Polyphenol Oxidase Enzyme}

The activity of polyphenol oxidase enzyme was observed to be very low during the early maturation stages; however, the activity seemed to be considerably enhanced at later stages of maturation. On the contrary, PPO activity level was observed to be increased by nearly four orders of magnitude upon maturation and reached to a maximum at Tamar stage (Figure 4). The enzyme activity of polyphenol oxidase started to decrease, as the sukkari date matures further. Figure 4 showed the changes in protein content of sukkari fruit at the various stages of maturation.

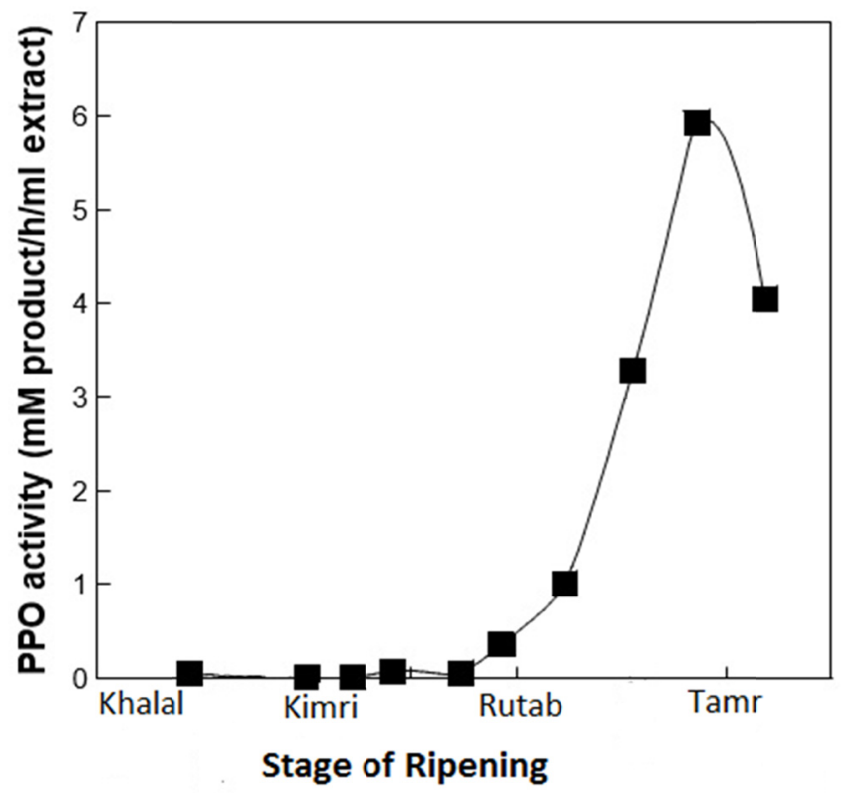

Figure 4. Polyphenol oxidase activity of sukkari during maturation

\subsubsection{Role of Amylase}

Amylase plays an essential role in giving a sweeter taste to the fruits. The activity of amylase enzyme decreases during the maturation process of sukkari dates; however, there is an enhancement in the amylase activity during the stages of rutab and Tamar (Figure 5). 


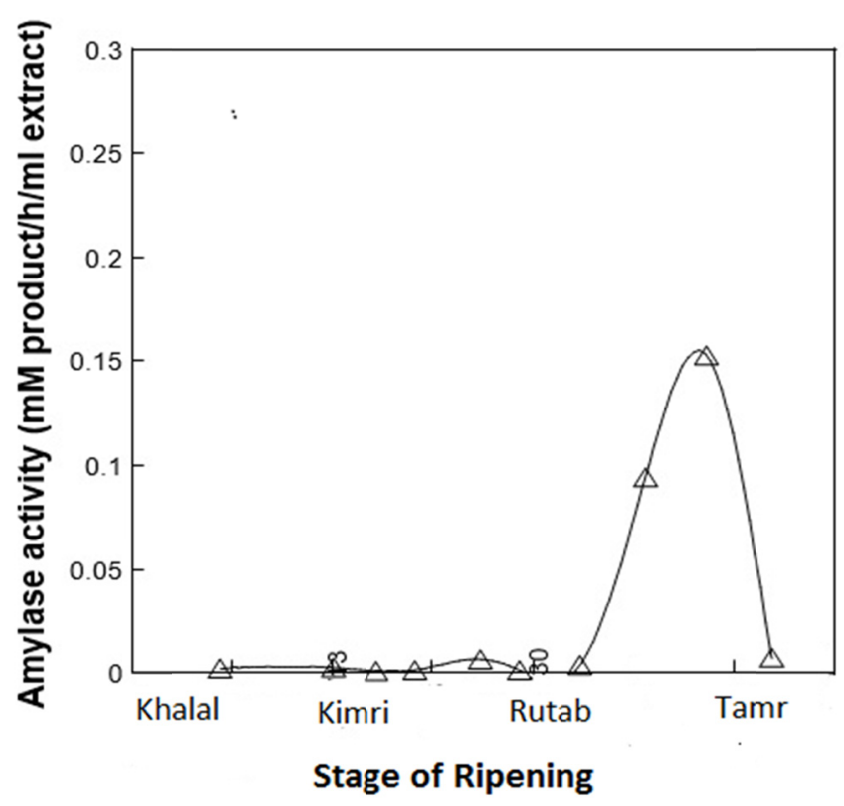

Figure 5. The change in amylase activity at various stages of sukkari maturation

\subsubsection{Pectinase and Cellulase Enzyme Activities}

It was examined that pectinase activity was likely to be associated with the maturation of fruits (Figure 6).

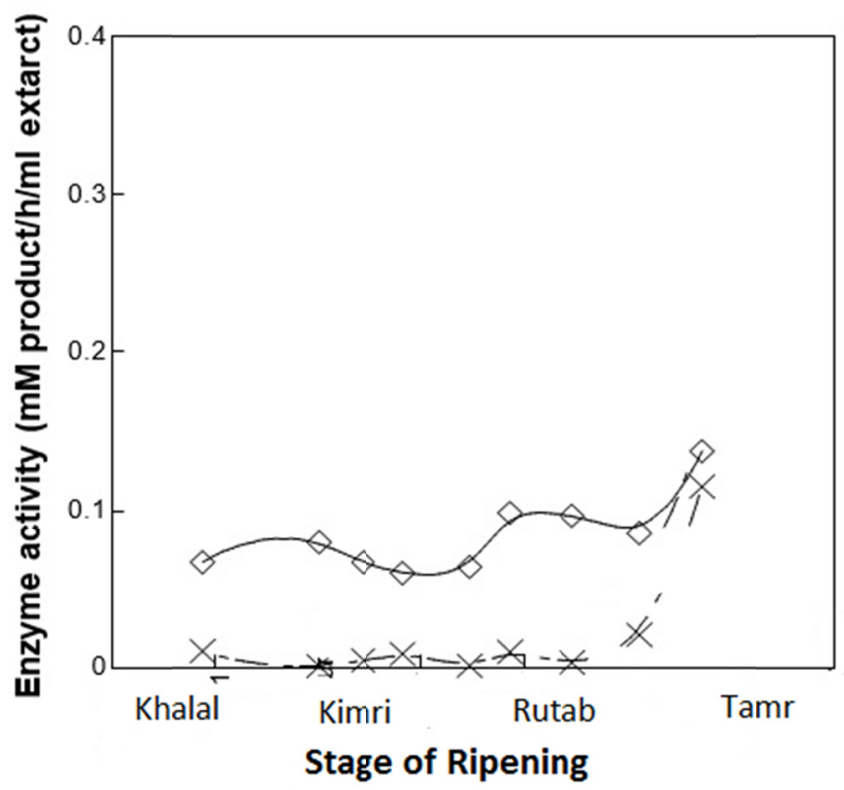

Figure 6. Changes in pectinase and cellulase activities of sukkari. Extracts of sukkari samples corresponding to the various stages of maturation were assayed for pectinase or cellulase activities as described in the method's section

\subsection{Biochemical Changes in Hilwa Dates}

Hilwa date is usually found in Madina, Hail and the central regions of Saudi Arabia. The evaluation of biochemical changes in hilwa date fruits was conducted during different maturation stages. Hilwa date fruit was in a way different, as it turned into red color during the maturity stage of rutab or khalal, as shown in Figure 7. 


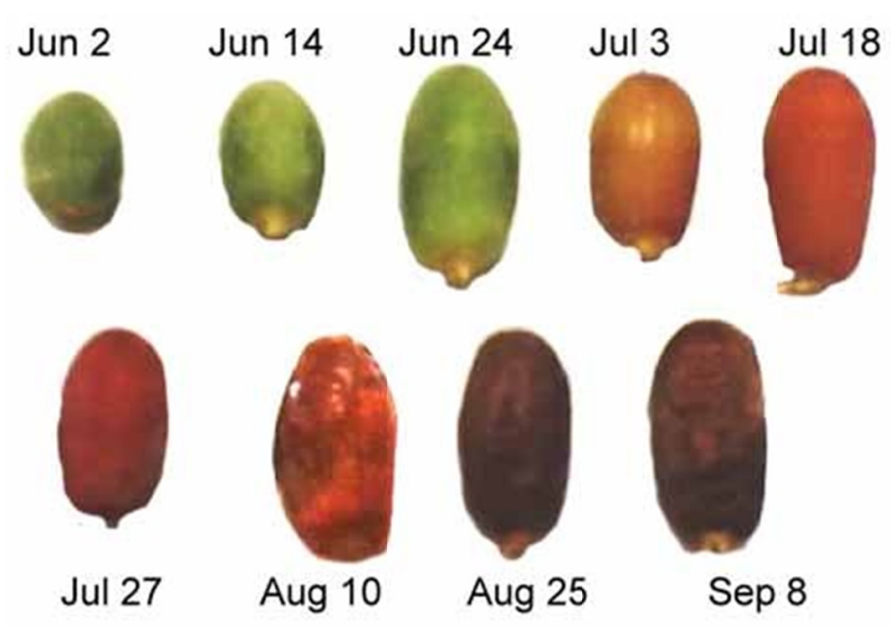

Figure 7. Hilwa date fruit at various stages of maturation

\subsubsection{Weight}

An increase in the weight of hilwa date fruits was evaluated during the early stages of maturation to have a maximum weight of $11 \mathrm{gm}$ to $13 \mathrm{gm}$. The weight of hilwa dates has been raised to $11 \mathrm{gm}$ from $5.6 \mathrm{gm}$. Conversely, the weight of hilwa was observed to decline during later maturation stages (Figure 8). Moreover, the weight of hilwa dates seemed to be declined during the Tamar stage, which generally attributes to the loss of water.

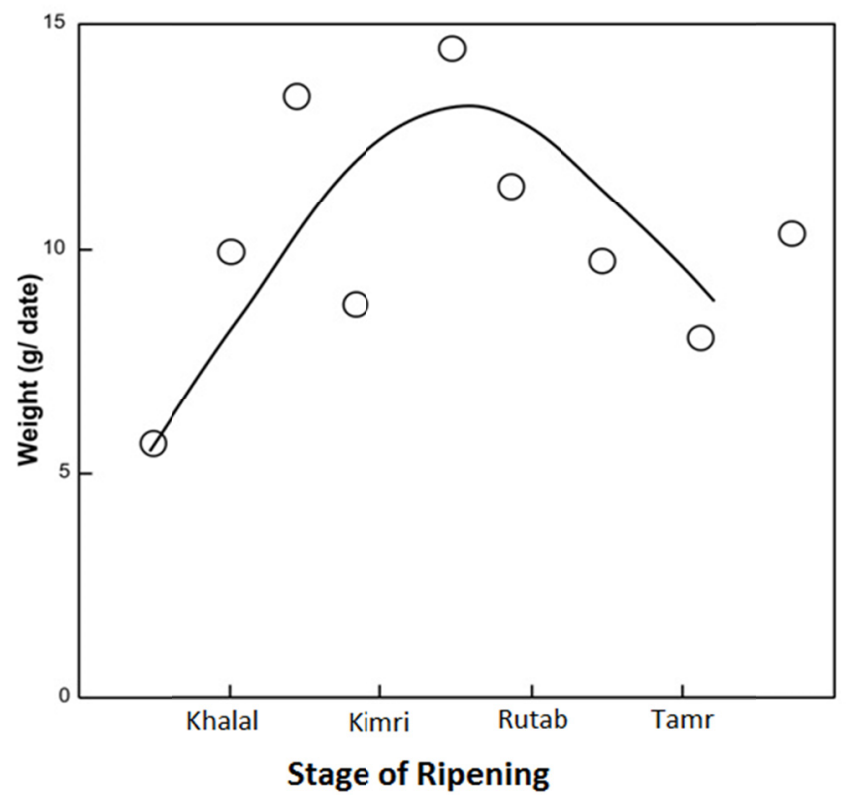

Figure 8 . Weight of one hilwa date at various stages of maturation

\subsubsection{Polyphenol Oxidase Activity}

It was observed to have low levels of activity during the initial maturation stage when polyphenol oxidase activity was investigated in hilwa dates (Figure 9). In contrast, a significant enhancement was observed upon maturation in enzyme activity of polyphenol oxidase, which reached a maximum level during the stage of Tamar. 


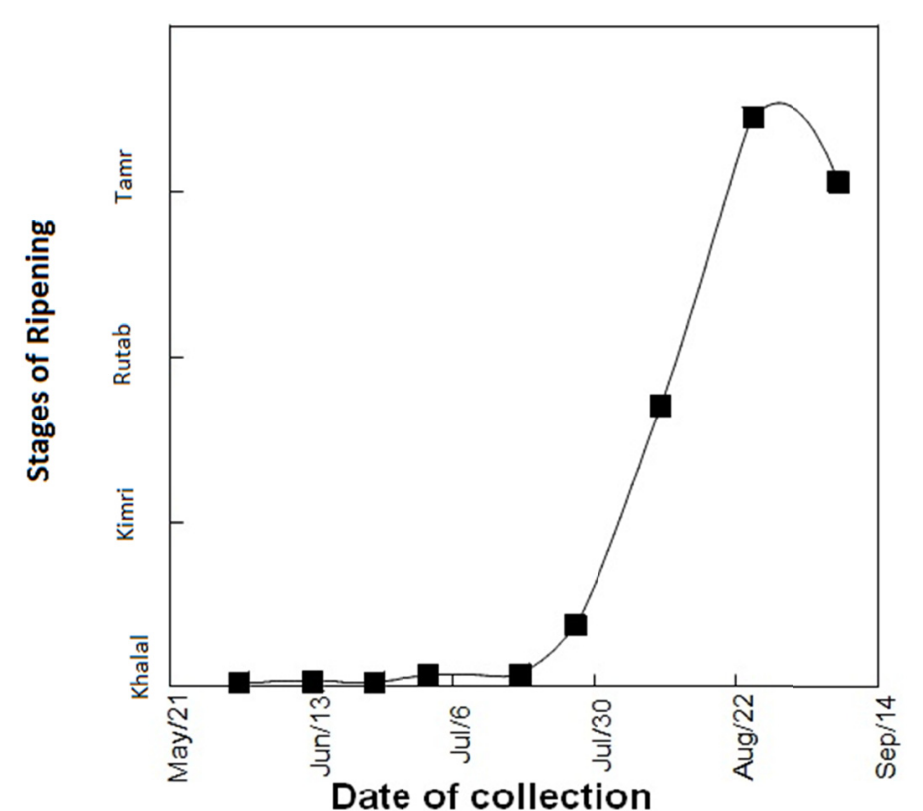

Figure 9. Soluble protein of hilwa fruit during various stages of maturation

\subsubsection{Amylase Activity}

It was observed that aqueous extracts of hilwa had low levels of amylase activities when the date fruits were in red and green maturation stages. Moreover, amylase activity enhanced rapidly during Rutab and Tamar stages (Figure 10).

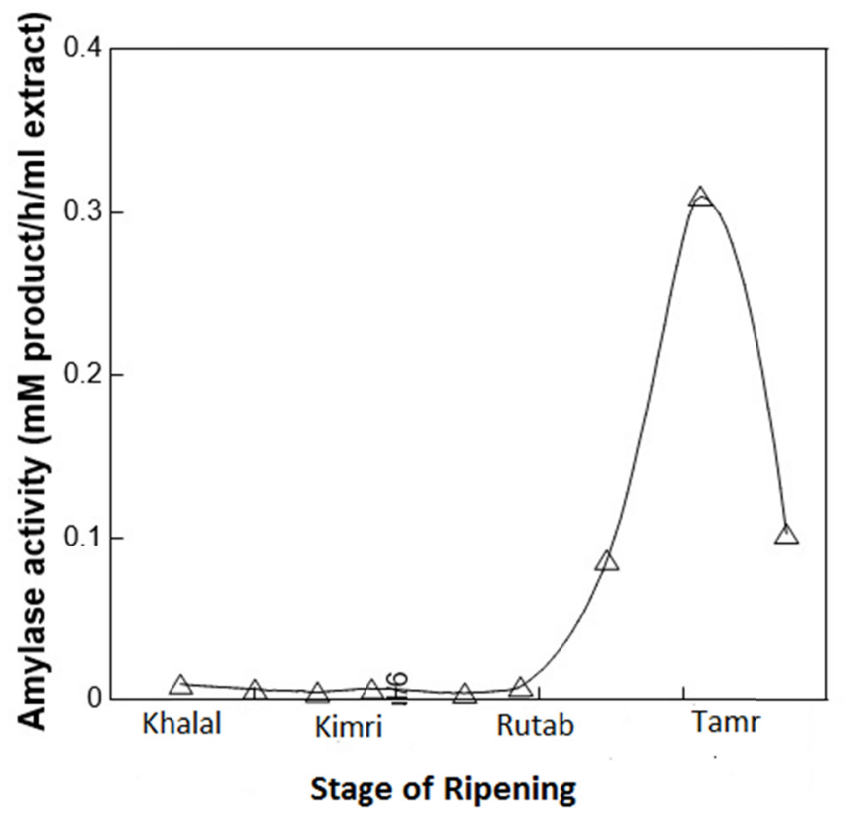

Figure 10. Amylase activity in aqueous extracts of hilwa during maturation

\subsubsection{Activity of Pectinase and Cellulase}

The pectinase activity was observed with definite and low level elements while considering the enzymes of pectinase and cellulase in the maturation of hilwa fruit during different maturation stages. There were very little variations during different stages of maturation in pectinase activity of hilwa dates (Figure 11). At the final stage of maturation, an apparent increase in the cellulase activity was also observed. 


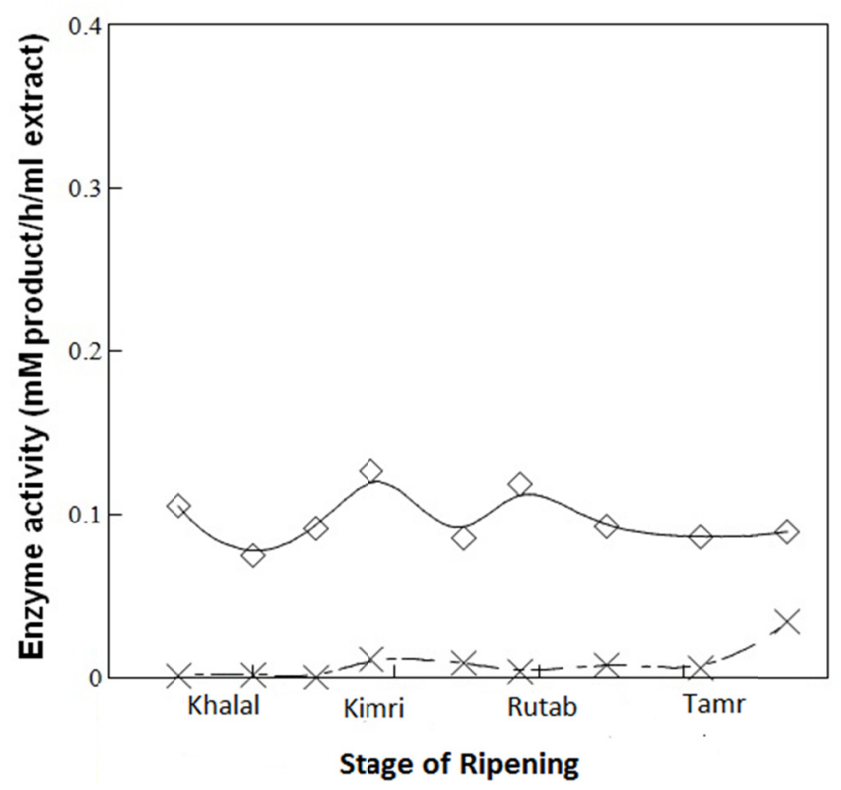

Figure 11. Pectinase and cellulase activity of hilwa extracts during maturation. Extracts of hilwa samples corresponding to the various stages of maturation were assayed for pectinase or cellulase activities as described in the method's section

Date palm fruits were observed to assess the significance of high nutrient content as well as the presence of bioactive compounds. These bioactive compounds include polyphenols, such as phenolics, flavonoids and tannins. One of the most striking aspects of sukkari dates maturation procedure was the difference in the degree of enzyme inductions. The activity of all the enzymes considered in this study can be observed in Figure 12. The enzyme activity of polyphenol oxidase was 15 to 30 folds greater, as compared to the amylase activities (Figure $13)$.

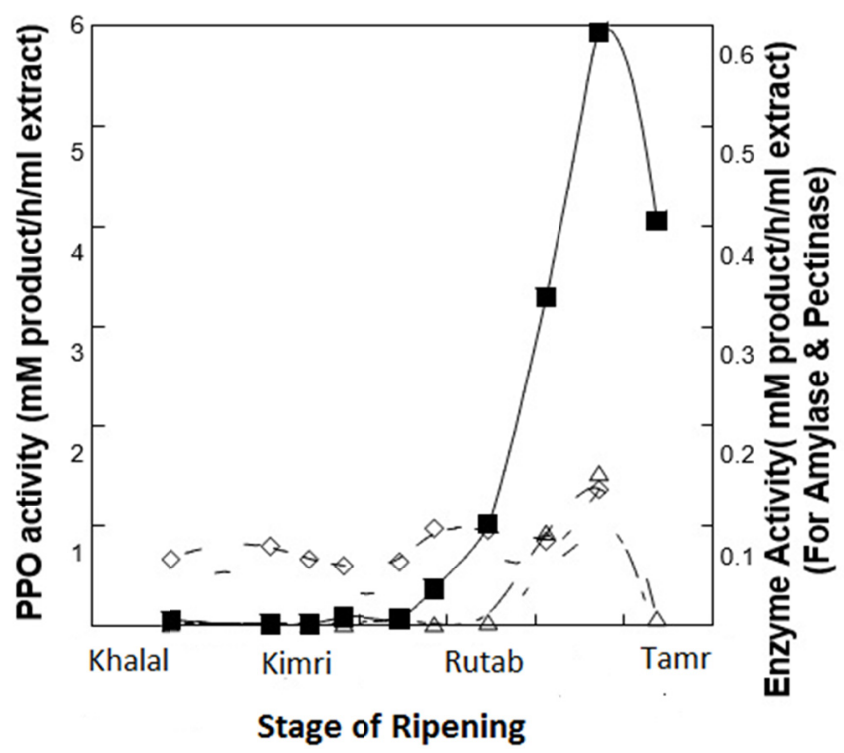

Figure 12. Changes in enzymatic activities of sukkari during maturation. This figure contrasts the change in enzymatic activities of amylase, Pectinase, polyphenol oxidase during maturation of sukkari date fruit. The scale on the left is applicable to PPO activity only 


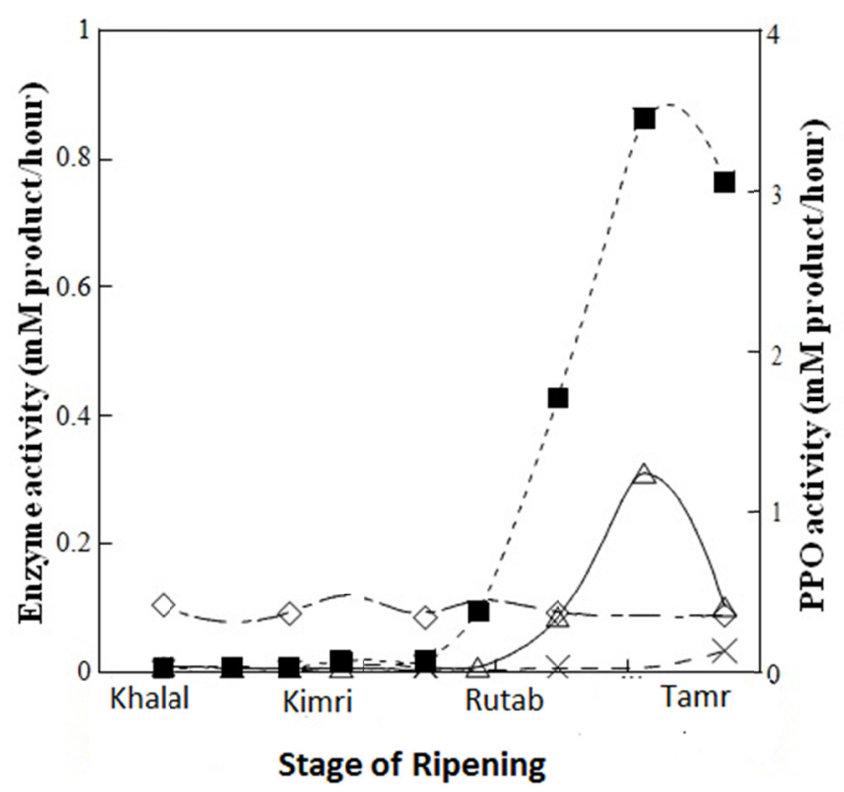

Figure 13. Changes in enzymatic activities of Hilwa at various stages of maturation. This figure contrasts the change in enzymatic activities of amylase, Pectinase, polyphenol oxidase, and cellulase during maturation of hilwa date fruit

\section{Discussion}

The study evaluated the biochemical changes in the date fruits such as sukkari date and hilwa dates. Considering the sukkari date, various samples showed the definite development of color from green to yellow and then to dark brown. Whereas, the results of hilwa dates showed that its color was red color during the maturity stage of rutab or khalal. The change in color is based on the sugar content, as well as the low moisture content, which darkens the colour similar to the study outcomes of Lobo, Yahia, and Kader (2013). The study results also illustrate that as the Sukkari dates matured, their weight enhanced from $3.7 \mathrm{gm}$ to $9.7 \mathrm{gm}$. However, there is a decrease of $7.4 \mathrm{gm}$ in the weight of Sukkari dates at the stage of final maturation. This is parallel to the study of Zakaria et al. (2012) who evaluated the chemical properties of the fruit mango, and observed its increase in weight at the final stage of maturation.

Moreover, these outcomes were observed to have similarity with the results, which were reported by Barreveld (1993). Hilwa Date maximum weight of $11 \mathrm{gm}$ to $13 \mathrm{gm}$ from $5.6 \mathrm{gm}$ was evaluated in the early maturation stage though it also declines in the later maturation. The decrease in weight during the transformation of sukkari from rutab to Tamar stage seemed to be attributed to the loss of water. Lobo, Yahia, and Kader (2013) supported the findings based on the fact that the fruit moisture content decreases with an increase in its sugar content.

In the sukkari date, as per the results, there was an increase in the protein contents at the Tamar stage. The highest content was recorded as $3.4 \mathrm{mg}$ protein $/ \mathrm{g}$, during the final maturity stage in the samples, which was also evidenced from past studies (Sood, Wagle, \& Dhindsa; Al-Hooti et al., 2002). The study of Al Tamim (2014) also endorsed the findings as it exhibited the low protein content in sukkari date fruits. The increase in protein content at the Tamar stage is also exhibited in the study of Mortazavi, Azizollahi, and Moallemi (2015) who examined the maturity stages of the Gantar', 'Deiri' and 'Shakar' fruit.

The results present that the activity of polyphenol oxidase enzyme in the sukkari date was very low during the early maturation stages. It increased in the later maturation stages whereas it decreased in the final maturity stage. The findings also demonstrated the increased PPO activity level with stage progression. The same results were found for the Hilwa date, which has low levels of activity during the initial maturation stage though it increased in its maturation and decrease at Tamar stage.

The findings of the study are endorsed by Eid et al. (2013), which illustrate that as the date fruit progresses, the polyphenols content at the kimri stage is maximum i.e. when it is unripe while at the final stage it remains minimum and can be eaten at Tamar stage. In addition, the outcomes of the study showed that in the sukkari dates, the study shows that there is amylase in the maturation stage though it increases in the stages of rutab and 
Tamar. Hilwa had low levels of amylase activities in the maturation stage although its activity enhanced rapidly during Rutab and Tamar stages. The induction of amylase activities seemed to be better in contrast with the sukkari dates. The decline in amylase activity with the further maturation of date fruit can be classified to several factors including transient expression, protein degradation, or senescence of fruit as evident by the low moisture content.

As per the sukkari date, the pectinase and cellulase enzyme activities has increased as the date ripens, but decreases in the final maturity stage. The findings have been supported by Brummell and Harpster (2001), which reported the similar results. Whereas, in the maturation of hilwa, definite and low level elements were recorded though trivial variation in the stages of maturation. Furthermore, the aqueous extracts of hilwa fruits did not exhibit the significant activity of cellulase. At the final stage of maturation, an apparent increase in the cellulase activity was also observed.

\section{Conclusion}

Polyphenol oxidase is a significant and major component for the maturation of date fruits. It demonstrated low levels of polyphenol oxidase during Kimri and Khalal stages; whereas, there is a significant enhancement in the level of polyphenol oxidase at the stage of maturity, i.e. the Tamar stage. Moreover, low levels in amylase enzymes have also been investigated during earlier stages, and high levels were observed at the stages of rutab and Tamar. Low activity levels in polyphenol oxidase have been observed at an earlier stage of maturation and the amylase activities are observed to be increased when the maturation process is in its final stage of maturation. From these enzyme activities, pectinase activity has been observed to have a slight fluctuation during the maturation stages.

On the contrary, some particular, as well as sudden bursts of activities, have been shown by the amylase and polyphenol oxidase activities during final stages of maturation, which is likely to be followed by the abrupt decline. Besides this, certain astounding differences in quantitative data have been observed at the levels of induction. It has been evaluated through quantitative outcomes that the activity of polyphenol oxidase was 40 to 100 folds higher, as compared to the pectinase, cellulase, or amylase during any maturation stage. The significance of this observation remained unknown; however, polyphenol oxidase activity has been clearly indicated as a major player in the maturation of sukkari date fruit. For the enzyme activities of polyphenol oxidase, amylase, cellulase, and pectinase, the results are likely to be explained in terms of transient inductions, where the polyphenol oxidase enzyme activity increased to two folds.

\section{Acknowledgements}

The authors are very thankful to all the associated personnel in any reference that contributed in/for the purpose of this research. The authors declare no conflict of interest. The study is not funded through any source.

\section{References}

Al Tamim, E. A. (2014). Comparative study on the chemical composition of Saudi Sukkari and Egyptian Swei date palm fruits. J. American Science, 10(6), 149-153.

Al-Alawi, R. A., Al-Mashiqri, J. H., Al-Nadabi, J. S., Al-Shihi, B. I., \& Baqi, Y. (2017). Date palm tree (Phoenix dactylifera L.): Natural products and therapeutic options. Frontiers in Plant Science, 8, 845. https://doi.org/ 10.3389/fpls.2017.00845

Al-Hooti, S. N., Sidhu, J. S., Al-Saqer, J. M., \& Al-Othman, A. (2002). Chemical composition and quality of date syrup as affected by pectinase/cellulase enzyme treatment. Food Chemistry, 79, 215-20. https://doi.org/ 10.1016/S0308-8146(02)00134-6

Al-Khalifah, N. S. (2012). First Arab Palm Conference on the development of date palm and dates sector in the Arab world. Emirates Journal of Food and Agriculture, 24(5), II.

Awad, M. A., Al-Qurashi, A. D., \& Mohamed, S. A. (2011). Biochemical changes in fruit of an early and a late date palm cultivar during development and maturation. International Journal of Fruit Science, 11, 167-183. https://doi.org/10.1080/15538362.2011.578520

Baliga, M. S., Baliga, B. R., Kandathil, S. M., Bhat, H. P., \& Vayalil, P. K. (2011). A review of the chemistry and pharmacology of the date fruits (Phoenix dactylifera L.). Food Research International, 44, 1812-1822. https://doi.org/10.1016/j.foodres.2010.07.004

Barreveld, W. H. (1993). Date palm products. Agricultural Services Bulletin (Vol. 101). FAO, Rome.

Benmeddour, Z., Mehinagic, E., Le Meurlay, D., \& Louaileche, H. (2013). Phenolic composition and antioxidant 
capacities of ten Algerian date (Phoenix dactylifera L.) cultivars: A comparative study. Journal of Functional Foods, 5(1), 346-354. https://doi.org/10.1016/j.jff.2012.11.005

Bradford, M. M. (1976). A rapid and sensitive method for the quantitation of microgram quantities of protein utilizing the principle of protein-dye binding. Anal Biochem, 72, 248-254. https://doi.org/10.1016/00032697(76)90527-3

Brummell, D. A., \& Harpster, M. H. (2001). Cell wall metabolism in fruit softening and quality and its manipulation in transgenic plants. In Plant Cell Walls, 311-340. https://doi.org/10.1007/978-94-010-06 68-2 18

Eid, N. M., Al-Awadi, B., Vauzour, D., Oruna-Concha, M. J., \& Spencer, J. P. (2013). Effect of cultivar type and maturation on the polyphenol content of date palm fruit. Journal of Agricultural and Food Chemistry, 61, 2453-2460. https://doi.org/10.1021/jf303951e

Haider, M. S., Khan, I. A., Jaskani, M. J., Naqvi, S. A., \& Khan, M. M. (2014). Biochemical attributes of dates at three maturation stages. Emirates Journal of Food and Agriculture, 26, 953. https://doi.org/10.9755/ ejfa.v26i11.18980

Lobo, M. G., Yahia, E. M., \& Kader, A. A. (2013). Biology and Postharvest Physiology of Date Fruit. Dates: Postharvest Science, Processing Technology and Health Benefits, 57-80. https://doi.org/10.1002/9781118 292419.ch3

Miller, G. L. (1959). Use of dinitrosalicylic acid reagent for determination of reducing sugar. Anal Chem, 426-428. https://doi.org/10.1021/ac60147a030

Mortazavi, S. M. H., Azizollahi, F., \& Moallemi, N. (2015). Some Quality Attributes and Biochemical Properties of Nine Iranian Date (Phoenix dactylifera L.) Cultivars at Different Stages of Fruit Development. International Journal of Horticultural Science and Technology, 2(2), 161-171.

Rastegar, S., Rahemi, M., Baghizadeh, A., \& Gholami, M. (2012). Enzyme activity and biochemical changes of three date palm cultivars with different softening pattern during maturation. Food Chemistry, 134, 1279-1286. https://doi.org/10.1016/j.foodchem.2012.02.208

Sood, D. R., Wagle, D. S., \& Dhindsa, K. S. (1982). Compositional variations in dried datepalm fruit varieties (Phoenix dactylifera). Indian Journal of Nutrition and Dietetics.

Torun, H., Kolcuoglu, Y., Ayaz, F. A., Colak, A., \& Glew, R. H. (2015). Characterization of polyphenol oxidase during three maturation stages of an eggplant (Solanum melongena L.) fruit: A local type in northeast Anatolia. Turkish Journal of Biochemistry, 40, 44-50. https://doi.org/10.5505/tjb.2015.27146

Trabzuni, D. M., Ahmed, S. E. B., \& Abu-Tarboush, H. M. (2014). Chemical composition, minerals, and antioxidants of the heart of Date Palm from three Saudi cultivars. Food and Nutrition Sciences, 5(14), 1379. https://doi.org/10.4236/fns.2014.514150

Zakaria, A., Shakaff, A. Y. M., Masnan, M. J., Saad, F. S. A., Adom, A. H., Ahmad, M. N., ... Kamarudin, L. M. (2012). Improved maturity and ripeness classifications of magnifera indica cv. harumanis mangoes through sensor fusion of an electronic nose and acoustic sensor. Sensors, 12(5), 6023-6048. https://doi.org/ $10.3390 / \mathrm{s} 120506023$

\section{Abbreviation}

BSA: bovine serum albumin; PPO: Polyphenol oxidase; DNS: Dinitrosalicylic acid; UK: United Kingdom.

\section{Copyrights}

Copyright for this article is retained by the author(s), with first publication rights granted to the journal.

This is an open-access article distributed under the terms and conditions of the Creative Commons Attribution license (http://creativecommons.org/licenses/by/4.0/). 